\title{
Economic Outcomes of Pharmacist Prescribing Total Parenteral Nutrition at Ministry of Health in Saudi Arabia
}

\author{
Yousef Ahmed Alomi* iD, The \\ Former General Manager of General \\ Administration of Pharmaceutical Care. \\ Former Head, National Clinical Pharmacy \\ and Pharmacy Practice, Former Head, \\ Pharmacy R\&D Administration, Ministry of \\ Health, Riyadh, SAUDI ARABIA. \\ Mona Awad Alanazi, IV admixture \\ and TPN units, Pharmacy services, Prince \\ Mohammad Bin Abdulaziz Hospital \\ Riyadh, SAUDI ARABIA. \\ Faiz A. Bahadig, Informatics Pharma- \\ cist, Pharmaceutical Care Department, \\ King Abdul-Aziz Medical, City-WR-Jeddah, \\ Ministry of National Guard, SAUDI ARABIA.

\section{Correspondence:} \\ Dr. Yousef Ahmed Alomi, The Former \\ General Manager of General Administration \\ of Pharmaceutical Care, Former Head, \\ National Clinical Pharmacy and \\ Pharmacy Practice, Former Head, \\ Pharmacy R\&D Administration, Ministry of \\ Health, Riyadh-11392, SAUDI ARABIA.
}

Phone no: +966 504417712

E-mail:yalomi@gmail.com
Received: 10-11-2018

Approved: 19-3-2019

Copyright: (c) the author(s),publisher and licensee Pharmacology, Toxicology and Biomedical Reports. This is an open-access article distributed under the terms of the Creative Commons Attribution NonCommercial License, which permits unrestricted non-commercial use, distribution, and reproduction in any medium, provided the original work is properly cited.

This is an open access article distributed under the terms of the Creative Commons Attribution-NonCommercial-ShareAlike 4.0 License

Access this article online

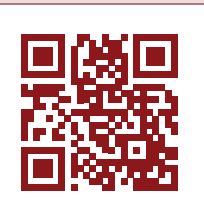

www.ptbreports.org

DOI:

10.5530/PTB.2019.5.35

\begin{abstract}
Objectives: In 2013, The General Administration of Pharmaceutical Care started the National Total Parenteral Nutrition (TPN) Program in Saudi Arabia. The pharmacist can provide neonates' TPN services. In this study, we aimed to estimate the economic outcomes and cost avoidance in relation to pharmacist prescribing TPN. Methods: A total of 20 hospitals provide TPN services for neonates, pediatrics and adult patients. Cost avoidance stimulation in relation to the pharmacist prescribing and running neonates, pediatrics TPN services and replacement physician of a pharmacist as prescriber with adults TPN services. All costs were calculated by using US dollar currency. One-way sensitivity analysis was conducted for a list of discount prices and variety of wage cost with $10-20 \%$. Results: The total annual estimated cost avoidance of pharmacist by providing TPN services for 20 hospitals for all types of patients was $(1,569,865.40$ USD) and with a discount of $10-20 \%$, it was $(1,412,878.86-1,255,892.32$ USD). Of those, the total annual estimated cost avoidance of pharmacist providing the TPN services for 20 hospitals for neonates was $(562,027.40$ USD) and with discount of $10-20 \%$, it was $(505,824.66$ $449,621.92$ USD). The total annual estimated cost avoidance of pharmacist providing the TPN services for 20 hospitals for adults was $(523,337.00$ USD) and with discount of $10-20 \%$, it was $(471,003.30$ $418,669.60$ USD). The total annual estimated cost avoidance of pharmacist providing the TPN services for 20 hospitals for pediatrics was $(484,501.00$ USD) and with a discount of $10-20 \%$, it was $(436,050.90-$ $387,600.80$ USD). Conclusion: The pharmacist prescribing TPN prevents high economic burden on the healthcare system at Ministry of Health. Expanding the role of a pharmacist in the nutrition support services with an emphasis on prescribing TPN services is highly recommended at healthcare institutions in the Kingdom of Saudi Arabia.
\end{abstract}

Key words: Economic, Outcomes, Cost avoidance, Pharmacist, Prescribing, Total Parenteral Nutrition, Ministry of Health, Saudi Arabia.

\section{INTRODUCTION}

The pharmacy profession development quickly over the past years in the Kingdom of Saudi Arabia. Previously, the pharmacist started working in the drug manufactures to only responsible for dispensing of medications. All pictures of pharmacy profession has dramatically changed after the concept of pharmaceutical care has changed. ${ }^{1}$ It starts from patient assessment through medications dispensing and monitoring the drug-related problems after dispensing. ${ }^{2}$ In recent years, pharmacists have started prescribing medications including Total Parenteral Nutrition (TPN). ${ }^{3,4}$ The role of a pharmacist in the preparation and dispensing of TPN is well-known..$^{5}$ The clinical and economic impact of the pharmacist with TPN processes has been well studied by the local and international research groups. ${ }^{6-9}$ However, the economic impact of the pharmacist prescribing TPN rarely investigated in practice ${ }^{5,10}$ Few studies have investigated the role of the pharmacist in prescribing TPN with their impact and benefits. ${ }^{6,11}$ To the best of our knowledge, there is no study about the cost avoidance by pharmacist prescribing and providing TPN services which has been published in Saudi Arabia, or the Gulf, or in the Middle Eastern countries..$^{11}$ Moreover, very few the international investigation discussed the topic. Therefore, in this study, we aimed to estimate economic outcomes and cost avoidance of pharmacist prescribing TPN in the KSA.

\section{METHODS}

This is a simulation study of 20 hospitals which provided TPN services for neonates, pediatrics and adult patients. Cost avoidance due to pharmacist prescribing and providing TPN services to neonates and pediatrics units and replacement physician with adults' TPN services. All information was related to 20 hospitals derived from previous studies published by the first author. ${ }^{10,12,13}$ The average number of orders per day per hospital was 5.5 daily orders for neonates, 2.05 daily orders for pediatrics and 2.075 daily orders for adults. The cost of TPN services was calculated based on a 280-bed hospital in Riyadh city, Saudi Arabia. The hospital has several specialties including adult's endocrinology, adults nephrology, pediatrics, adults cardiology, adults internal medicine, adults surgery, adults critical care unit, Neonatal Intensive Care Units (NICU), Pediatrics Intensive Care Units (PICU) and obstetrics and gynecology. The hospital provides ambulatory care services and emergency services in relation to above specialties. In addition, the hospital is various pharmaceutical services including inpatient pharmacy, ambulatory care pharmacy, TPN services, drug information services and computerized physician order entry system at inpatient 
Table 1: Total cost of total parenteral nutrition (TPN) services at the hospital.

\begin{tabular}{|c|c|c|c|c|c|c|}
\hline \multirow{2}{*}{$\begin{array}{l}\text { Type of cost } \\
\text { Personal }\end{array}$} & \multicolumn{2}{|c|}{$\begin{array}{l}\text { Cost Neonates TPN services per } \\
\text { day (USD) }\end{array}$} & \multicolumn{2}{|c|}{$\begin{array}{c}\text { Cost Pediatrics TPN services } \\
\text { per day (USD) }\end{array}$} & \multicolumn{2}{|c|}{$\begin{array}{l}\text { Cost Adults TPN services per day } \\
\text { (USD) }\end{array}$} \\
\hline & 76.24 & $9.69 \%$ & 76.24 & $13.82 \%$ & 76.24 & $11.03 \%$ \\
\hline Over Head cost & 387.83 & $49.30 \%$ & 121.17 & $21.96 \%$ & 279.83 & $40.48 \%$ \\
\hline Material and Supply & 112.47 & $14.30 \%$ & 110.47 & $20.02 \%$ & 108.30 & $15.67 \%$ \\
\hline Non-Salary cost & 13.48 & $1.71 \%$ & 13.48 & $2.44 \%$ & 13.48 & $1.95 \%$ \\
\hline Direct cost & 196.72 & $25.00 \%$ & 230.43 & $41.76 \%$ & 213.43 & $30.87 \%$ \\
\hline $\begin{array}{l}\text { Total cost services per day with clinical pharmacist } \\
\text { prescribing and monitoring }\end{array}$ & 786.74 & & 551.79 & & 691.28 & \\
\hline Total cost per day with $10 \%$ discount & 708.17 & & 496.61 & & 622.15 & \\
\hline Total cost per day with $20 \%$ discount & 629.39 & & 441.43 & & 553.02 & \\
\hline $\begin{array}{l}\text { Total cost per order day per hospital with clinical } \\
\text { pharmacist prescribing and monitoring }\end{array}$ & 143.04 & & 269.17 & & 333.15 & \\
\hline Total cost per order with $10 \%$ discount & 128.74 & & 242.25 & & 299.84 & \\
\hline Total cost per order with $20 \%$ discount & 114.43 & & 215.34 & & 266.52 & \\
\hline $\begin{array}{l}\text { Total cost services per day without clinical } \\
\text { pharmacist prescribing and monitoring }\end{array}$ & 863.74 & & 618.15 & & 762.97 & \\
\hline Total cost per day with $10 \%$ discount & 777.37 & & 556.34 & & 686.67 & \\
\hline Total cost per day with $20 \%$ discount & 690.99 & & 494.52 & & 610.38 & \\
\hline $\begin{array}{l}\text { Total cost per order day per hospital without } \\
\text { clinical pharmacist prescribing and monitoring }\end{array}$ & 157.04 & & 301.54 & & 367.70 & \\
\hline Total cost per order with $10 \%$ discount & 141.34 & & 271.39 & & 330.93 & \\
\hline Total cost per order with $20 \%$ discount & 125.63 & & 241.23 & & 294.16 & \\
\hline
\end{tabular}

and outpatient units. In 2009s, the pharmacy services established TPN services from the physician prescribing it to pharmacist reviewing the order, preparing it and dispensing it, to the nurse administering the preparation to the patients. TPN is prepared through sterile 797 standards and automated compounding facilities. The cost of TPN is calculated by counting the personal cost including the cost of doctor, pharmacist and pharmacy technician per hour and then the cost of preparation time of each TPN bag is calculated. Then, the total prices of the overhead cost for the bed and all machines were included to calculate the cost of TPN services. This also includes overhead cost such as rent, incubator, Laminar Flow Hood (LFH), TPN System Baxa (ME 2400), computer, USB Scanner, printer, Zebra label printer (Direct Thermal), equipment, refrigerator pass through, refrigerator TPN, gauge, room pressure and two lab chairs. In addition, the purchased materials and supplies plus non-salary cost including the average cost of empty TPN bag, one valve set, tubes, syringe $50 \mathrm{~mL}$, central venous catheter set, intravenous cannula (change every 3 days for 14.4 days), education and training time for pharmacist and pharmacy technician and TPN resources. The authors estimated the cost based on the purchased cost for the direct cost for TPN preparation and lipid as 2 in 1 TPN type administration method, the purchased prices of TPN lab tests with the average length of stay of neonates, pediatrics and adults. The medication prices were based on Gulf Corporation Council Countries (GCCC) tender prices version 36. The authors used Baxa system (ME2400) machines to calculate all active components of TPN orders, The the average estimated cost of preparation for six months TPN preparations All cost were calculated in US dollar currency. One-way sensitivity analysis was conducted for a discount of prices list and variety of wage cost with $10-20 \%$.

\section{RESULTS}

The estimated cost of TPN services running by the pharmacist for neonates was (786.74 USD). Of this, the majority of the cost was overhead cost (387.83 USD, 49.30\%) and with a discount of 10-20\%, it was (708.17629.39 USD) followed by direct cost (196.72 USD, 25.00\%) and material and supply cost (112.47 USD, 14.30\%). The estimated cost of TPN services for adult per day with the clinical pharmacist was (691.3 USD) and with a discount of $10-20 \%$, it was (622.15-553.02 USD). Of this, the majority of the cost was overhead cost (279.83 USD, $40.48 \%)$ followed by direct cost (213.43 USD, 30.87\%) and material and supply cost (108.3 USD, 15.67\%). The estimated per day cost of TPN services for pediatrics with the clinical pharmacist was (551.79 USD) and with a discount of $10-20 \%$, it was (496.61-441.43 USD). Of this, majority of the cost came from direct cost (230.43 USD, 41.76\%), followed by overhead cost (121.17 USD, 21.96\%) and material and supply (110.47 USD, 20.02\%) (Table 1).

The estimated cost of order per day per hospital with clinical pharmacist prescribing and monitoring TPN services for an adult was (333.15 USD ) and with a discount of $10-20 \%$, it was (299.84-266.52 USD). The estimated cost of order per day per hospital with clinical pharmacist prescribing and monitoring TPN services for pediatrics was (269.17 USD) and with a discount of 10-20\%, it was (242.25-215.34 USD). The estimated cost of order per day per hospital with clinical pharmacist prescribing and monitoring TPN services for neonates was (143.04 USD) and with a discount of 10-20\%, it was (128.74-114.43 USD) (Table 1).

The total annual estimated cost avoidance of pharmacist prescribing TPN services for neonates was (5,109.33 USD) and with a discount of 
Table 2: Total cost avoidance of pharmacist prescribing neonatal total parenteral nutrition (TPN) orders.

\begin{tabular}{|c|c|c|c|c|c|c|c|c|c|}
\hline \multirow[b]{2}{*}{ Type of cost } & \multicolumn{3}{|c|}{$\begin{array}{l}\text { Daily Cost of Neonates TPN orders } \\
\text { (USD) }\end{array}$} & \multirow[t]{2}{*}{$\begin{array}{c}\text { Total } \\
\text { annual } \\
\text { cost } \\
\text { avoidance }\end{array}$} & \multicolumn{3}{|c|}{$\begin{array}{c}\text { Daily Cost of Neonates TPN orders per } \\
\text { hospital (USD) }\end{array}$} & \multirow{2}{*}{$\begin{array}{c}\text { Total } \\
\text { annual } \\
\text { cost } \\
\text { avoidance } \\
\text { per } \\
\text { hospital }\end{array}$} & \multirow[t]{2}{*}{$\begin{array}{c}\text { Total } \\
\text { monthly cost } \\
\text { avoidance } \\
\text { per hospital }\end{array}$} \\
\hline & $\begin{array}{l}\text { Cost per } \\
\text { order }\end{array}$ & $\begin{array}{c}\text { Annual } \\
\text { cost with } \\
\text { pharmacist }\end{array}$ & $\begin{array}{c}\text { Annual } \\
\text { cost } \\
\text { without } \\
\text { pharmacist }\end{array}$ & & $\begin{array}{l}\text { Cost of } \\
\text { all orders } \\
\text { per day } \\
\text { per } \\
\text { hospital }\end{array}$ & $\begin{array}{c}\text { Annual } \\
\text { cost with } \\
\text { pharmacist }\end{array}$ & $\begin{array}{c}\text { Annual cost } \\
\text { without } \\
\text { pharmacist }\end{array}$ & & \\
\hline Personal & 13.86 & $5,059.56$ & $10,168.90$ & $5,109.34$ & 76.23 & $27,827.58$ & $55,928.95$ & $28,101.37$ & $2,341.78$ \\
\hline Over Head cost & 70.51 & $25,737.81$ & $25,737.81$ & 0.00 & 387.81 & $141,557.96$ & $141,557.96$ & 0.00 & 0.00 \\
\hline Material and Supply & 20.45 & $7,463.92$ & $7,463.92$ & 0.00 & 112.48 & $41,051.56$ & $41,051.56$ & 0.00 & 0.00 \\
\hline Non-Salary cost & 2.45 & 894.58 & 894.58 & 0.00 & 13.48 & $4,920.19$ & $4,920.19$ & 0.00 & 0.00 \\
\hline Direct cost & 35.77 & $13,055.05$ & $13,055.05$ & 0.00 & 196.74 & $71,802.78$ & $71,802.78$ & 0.00 & 0.00 \\
\hline Total Cost & 143.04 & $52,210.93$ & $57,320.26$ & $5,109.33$ & 786.72 & $287,160.12$ & $315,261.43$ & $28,101.32$ & $2,341.78$ \\
\hline $\begin{array}{l}\text { Total cost with } 10 \% \\
\text { discount }\end{array}$ & 128.74 & $46,989.84$ & $51,588.23$ & $4,598.40$ & 708.05 & $258,444.11$ & $283,735.29$ & $25,291.19$ & $2,107.60$ \\
\hline $\begin{array}{l}\text { Total cost with } 20 \% \\
\text { discount }\end{array}$ & 114.43 & $41,768.74$ & $45,856.21$ & $4,087.46$ & 629.38 & $229,728.10$ & $252,209.14$ & $22,481.06$ & $1,873.42$ \\
\hline
\end{tabular}

Table 3: Total cost avoidance of pharmacist prescribing pediatrics total parenteral nutrition (TPN) orders.

\begin{tabular}{|c|c|c|c|c|c|c|c|c|c|}
\hline \multirow[b]{2}{*}{ Type of cost } & \multicolumn{3}{|c|}{$\begin{array}{l}\text { Daily Cost of Pediatrics TPN orders } \\
\text { (USD) }\end{array}$} & \multirow[t]{2}{*}{$\begin{array}{c}\text { Total } \\
\text { annual } \\
\text { cost } \\
\text { avoidance }\end{array}$} & \multicolumn{3}{|c|}{$\begin{array}{c}\text { Daily Cost of Pediatrics TPN orders per } \\
\text { hospital (USD) }\end{array}$} & \multirow{2}{*}{$\begin{array}{c}\text { Total } \\
\text { annual } \\
\text { cost } \\
\text { avoidance } \\
\text { per } \\
\text { hospital }\end{array}$} & \multirow{2}{*}{$\begin{array}{c}\text { Total } \\
\text { monthly } \\
\text { cost } \\
\text { avoidance } \\
\text { per } \\
\text { hospital }\end{array}$} \\
\hline & $\begin{array}{l}\text { Cost } \\
\text { per } \\
\text { order }\end{array}$ & $\begin{array}{l}\text { Annual } \\
\text { cost with } \\
\text { pharmacist }\end{array}$ & $\begin{array}{c}\text { Annual cost } \\
\text { without } \\
\text { pharmacist }\end{array}$ & & $\begin{array}{l}\text { Cost of all } \\
\text { orders per } \\
\text { day per } \\
\text { hospital }\end{array}$ & $\begin{array}{l}\text { Annual } \\
\text { cost with } \\
\text { pharmacist }\end{array}$ & $\begin{array}{c}\text { Annual cost } \\
\text { without } \\
\text { pharmacist }\end{array}$ & & \\
\hline Personal & 37.19 & $13,574.44$ & $25,391.54$ & $11,817.10$ & 76.24 & $27,827.60$ & $52,052.65$ & $24,225.05$ & $1,053.26$ \\
\hline Over Head cost & 59.11 & $21,574.17$ & $21,574.17$ & 0.00 & 121.17 & $44,227.05$ & $44,227.05$ & 0.00 & 0.00 \\
\hline Material and Supply & 53.89 & $19,669.05$ & $19,669.05$ & 0.00 & 110.47 & $40,321.55$ & $40,321.55$ & 0.00 & 0.00 \\
\hline Non-Salary cost & 6.58 & $2,400.10$ & $2,400.10$ & 0.00 & 13.48 & $4,920.20$ & $4,920.20$ & 0.00 & 0.00 \\
\hline Direct cost & 112.40 & $41,027.78$ & $41,027.78$ & 0.00 & 230.43 & $84,106.95$ & $84,106.95$ & 0.00 & 0.00 \\
\hline Total Cost & 269.17 & $98,245.54$ & $110,062.63$ & $11,817.09$ & 551.79 & $201,403.35$ & $225,628.40$ & $24,225.05$ & $1,053.26$ \\
\hline Total cost with $10 \%$ discount & 128.74 & $88,420.99$ & $99,056.37$ & $10,635.38$ & 496.61 & $181,263.02$ & $203,065.56$ & $21,802.55$ & 947.93 \\
\hline Total cost with $20 \%$ discount & 114.43 & $78,596.43$ & $88,050.10$ & $9,453.67$ & 441.43 & $161,122.68$ & $180,502.72$ & $19,380.04$ & 842.61 \\
\hline
\end{tabular}

10-20\%, it was (4598.40-4087.46 USD). The total annual estimated cost avoidance of pharmacist prescribing TPN services per hospital for neonates was $(28,101.32$ USD) and with a discount of $10-20 \%$, it was (25,291.19-25,291.19 USD), whereas monthly estimated cost avoidance was (2341.78 USD) and with a discount of 10-20\%, it was (2107.60-1873.42 USD) (Table 2). The total annual estimated cost avoidance of pharmacist providing TPN services for pediatrics was (11,817.09 USD) and with a discount of $10-20 \%$, it was (10,635.38-9453.67 USD). The total annual estimated cost avoidance of pharmacist providing TPN services per hospital for pediatrics was (24,225.05 USD) and with a discount of $10-20 \%$, it was (21,802.55-19,380.04 USD), whereas monthly estimated cost avoid- ance was (1,053.26 USD) and with a discount of 10-20\%, it was (947.93842.61 USD) (Table 3). The total annual estimated cost burden of nonpharmacist providing TPN services for adults was (-12,610.53 USD) and with a discount of $10-20 \%$, it was (-11,349.48 to $-10,088.42$ USD). The total annual estimated cost burden of non-pharmacist providing TPN services per hospital for adults was (-26,166.85 USD) and with a discount of $10-20 \%$, it was $(-23,550.17$ to $-20,933.48$ USD), whereas monthly estimated cost burden was (-1,308.34 USD) and with a discount of 10-20\%, it was $(-1,177.51$ to $-1,046.67$ USD) (Table 4$)$. The total annual estimated cost avoidance of pharmacist providing TPN for 20 hospitals for all types of patients and for 20 hospitals was $(1,569,865.40$ USD) and with a 
Table 4: Total cost burden pharmacist non prescribing adult's total parenteral nutrition (TPN) orders.

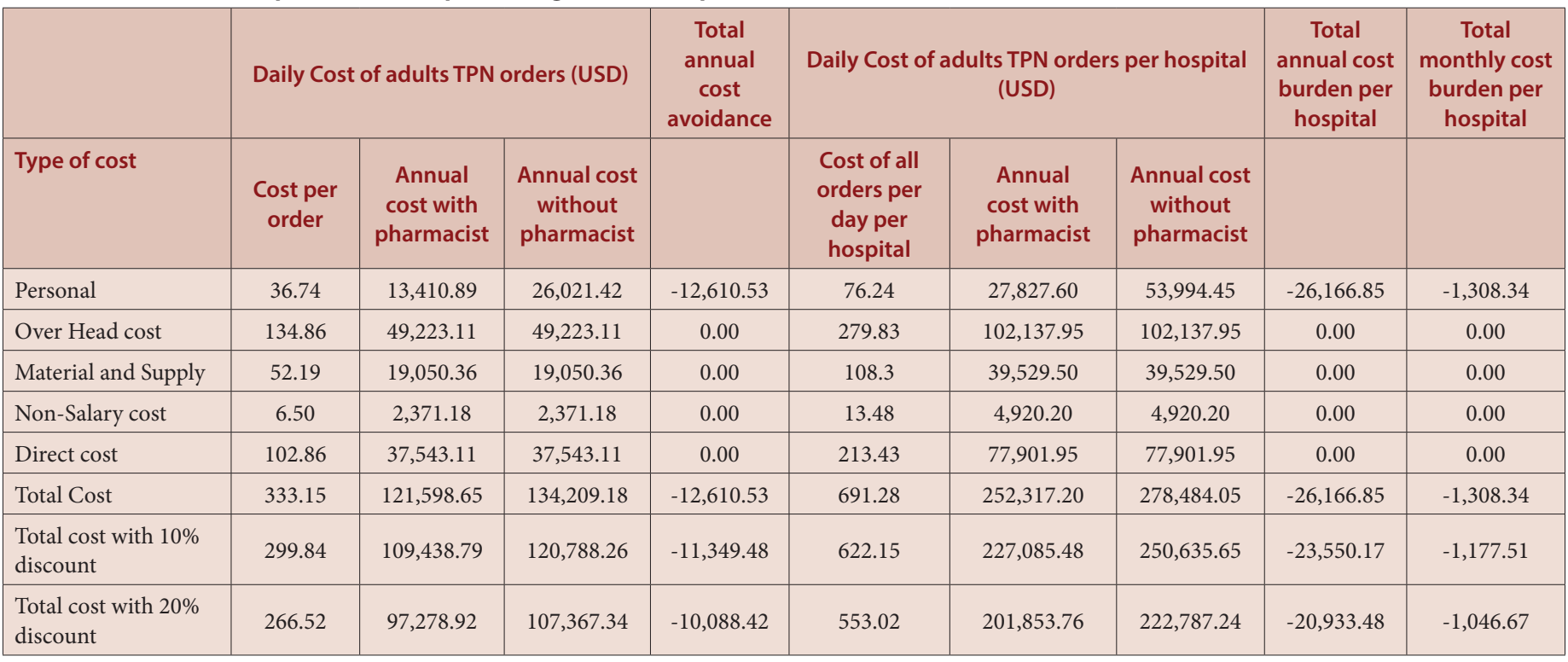

Table 5: Total annual cost avoidance with pharmacist prescribing and running total parenteral nutrition (TPN) services.

\begin{tabular}{|l|c|c|c|c|c|}
\hline $\begin{array}{l}\text { Type of } \\
\text { Patient }\end{array}$ & $\begin{array}{c}\text { Average number of } \\
\text { orders per day per } \\
\text { hospital }\end{array}$ & $\begin{array}{c}\text { Total annual cost } \\
\text { avoidance per } \\
\text { hospital }\end{array}$ & $\begin{array}{c}\text { Total annual cost } \\
\text { avoidance for } \\
\text { 20-hospital }\end{array}$ & $\begin{array}{c}\text { Total annual cost avoidance } \\
\text { for 20-hospital (10\%) } \\
\text { discount }\end{array}$ & $\begin{array}{c}\text { Total annual cost avoidance } \\
\text { for 20-hospital with (20\%) } \\
\text { discount }\end{array}$ \\
\hline Neonates & $5.5(57.14 \%)$ & $28,101.37$ & $562,027.40$ & $505,824.66$ & $449,621.92$ \\
\hline Pediatrics & $2.05(21.29 \%)$ & $24,225.05$ & $484,501.00$ & $436,050.90$ & $387,600.80$ \\
\hline Adults & $2.075(21.55 \%)$ & $-26,166.85$ & $-523,337.00$ & $-471,003.30$ & $-418,669.60$ \\
\hline Total & 9.625 & $78,493.27$ & $1,569,865.40$ & $1,412,878.86$ & $1,255,892.32$ \\
\hline
\end{tabular}

discount of $10-20 \%$, it was $(1,412,878.86-1,255,892.32$ USD). Of this, the total annual estimated cost avoidance of pharmacist providing TPN services for 20 hospitals for neonates (562,027.40 USD) with a discount of $10-20 \%$ was $(505,824.66-449,621.92$ USD). The total annual estimated cost avoidance of pharmacist providing TPN services for 20 hospitals and for adult patients was (523,337.00 USD) and with a discount of 10-20\%, it was (471,003.30-418,669.60 USD). The total annual estimated cost avoidance of pharmacist providing TPN services for 20 hospitals and for pediatric patients was (484,501.00 USD) and with a discount of $10-20 \%$, it was $(436,050.90-387,600.80$ USD) (Table 5).

\section{DISCUSSION}

The TPN services was started in the mid-1970s in KSA. ${ }^{14}$ In the early 1990s, the pharmacist used to provide TPN services for neonates along with preparation but only in the $\mathrm{MOH}$ hospitals. ${ }^{14}$ However, in the early 2000s, the complete TPN services including assessment, preparation, prescription and monitoring of services for adults was implemented. TPN services was started in the most prominent public hospital in Riyadh city. The fully automated compounding with Computerized Physician Oder Entry (CPOE) was started in the mid-2000s. The pharmacist prescribe TPN orders to adult surgical, medical and critical care units, whereas prescribing done by physician for all neonates' specialties. In this study, we aimed to estimate the cost avoidance of pharmacist prescribing TPN. The findings showed that the estimated cost reduced when pharmacists started prescribing TPN services than that of physicians, which might be related to the high personal cost of physicians. The highest cost reduction was recorded for neonates followed by pediatrics and neonates. This is expected because prescribing these services to neonatal or pediatric patients requires more time than that of adult patients. In the simulation of the data from 20 hospitals providing TPN based on the previous study done the same authors. ${ }^{10,12,13}$ The highest cost saving or avoidance was recorded for neonates followed by adult and pediatric patients. A previous study reported lower costs than that of this study. ${ }^{11}$ This might be because TPN services were newly established with pharmacist as the prescriber. The estimated cost avoidance of pharmacist prescribing TPN was underestimated because most of the cost avoidance was recorded for the personal cost, which is related to salary only. The salary of a medical doctor is much higher than that of a pharmacist. We did not include cost avoidance of prevention drug-related problems. Moreover, the authors did not include the cost that was for appropriate indication or appropriate type of nutrition elements. We highly recommend to compare estimated cost avoidance between physicians and pharmacist in future studies in the healthcare institution of the MOH in the KSA.

\section{CONCLUSION}

In this study, we estimated the cost saving of pharmacist prescribing TPN services to neonates, pediatrics and adults. High cost saving of pharmacist prescribing TPN order in Saudi Arabia. Utilization of pharmacists and expanding their role in the nutrition support services in the governmental and private healthcare intuitions is required to fit with goals of New Saudi vision 2030 and MOH strategic plan in the KSA.

\section{ACKNOWLEDGEMENT}

None. 


\section{CONFLICT OF INTEREST}

The authors declare no conflict of interest.

\section{ABBREVIATIONS}

TPN: Total parenteral nutrition; KSA: Kingdom of Saudi Arabia; MOH: Ministry of Health; NICU: Neonatal Intensive Care Units; PICU: Pediatrics Intensive Care Units; LFH: Laminar Flow Hood; GCCC: Gulf Corporation Council Countries; USD: US Dollars; CPOE: Computerized Physician Oder Entry.

\section{ORCID ID}

Yousef Ahmed Alomi, (iD https://orcid.org/0000-0003- 1381-628X

\section{REFERENCES}

1. American Society of Health-System Pharmacists. ASHP statement on pharmaceutical care. Am J Hosp Pharm. 1993;50(50):1720-3.

2. American Society of Health-System Pharmacists. ASHP guidelines on a standardized method for pharmaceutical care. Am J Heal Pharm. 1996;53(14):1713-6.

3. Gross Z. Pharmacist prescribing of parenteral nutrition. Hosp Pharm. 2005; $12: 17-20$

4. Pearson G, Yuksel N, Card D, Chin T, Gray M, Hawboldt J, et al. An Information Paper on Pharmacist Prescribing Within a Health Care Facility. Candian J Hosp Pharm. 2002;55(1):1-7
5. Alomi YA, Ajudaibi SM. National Survey of Total Parenteral Nutrition Practice in Saudi Arabia: Dispensing and Administration at $\mathrm{MOH}$ Hospitals. EC Nutr. 2016;(3-6):748-56.

6. Ragab MH, Al-Hindi MY, Alrayees MM. Neonatal parenteral nutrition: Review of the pharmacist role as a prescriber. Saudi Pharm J. 2016;24(4):429-40.

7. Katoue MG. Role of pharmacists in providing parenteral nutrition support: Current insights and future directions. Integr Pharm Res Pract. 2018;7:125-40.

8. Alomi YA, Fallatah AO, Al-Smail EH. Assessment of Clinical And Economic Outcomes of Pharmacist Intervention in Total Parenteral Nutrition Program In Saudi Arabia. Value Heal. 2016;19(7):A465.

9. Alomi YA, Fallatah AO. Economics outcomes of pharmacist managed Neonatal Total Parenteral Nutrition Services at Ministry of Health in Saudi Arabia. Value Heal. 2017;20(5):A42.

10. AlomiYA, Aljudaibi SM, Alghamd SJ. National Survey of Total Parenteral Nutrition Practice in Saudi Arabia: Prescribing and Transcribing at $\mathrm{MOH}$ Hospitals. EC Nutr. 2016;4(1):795-803.

11. Rafferty E, Yaghoubi M, Taylor J, Farag M. Costs and savings associated with a pharmacists prescribing for minor ailments program in Saskatchewan. Cost Eff Resour Alloc. 2017;15(1):2-5.

12. Alomi YA, Aljudaibi SM. National Survey of Total Parenteral Nutrition Practice in Saudi Ara-bia: Dispensing and Administration at $\mathrm{MOH}$ Hospitals. EC Nutr. 2016;3(6):748-56

13. Alomi YA, Aljudaibi SM. National Survey of Total Parentral Nutrition Practice in Saudi Arabia: Drug Monitoring and Patient Education at $\mathrm{MOH}$ Hospitals. EC Nutr. 2016;4(1):784-92.

14. Alomi YA. National Total Parenteral Nutrition Program at $\mathrm{MOH}$ in Saudi Arabia. EC Nutr. 2016;3:697-9. 